\title{
IMPROVING SCENARIO-TECHNIQUE BY A SEMI-AUTOMATIZED CONSISTENCY ASSESSMENT BASED ON PATTERN RECOGNITION BY ARTIFICIAL NEURAL NETWORKS
}

\author{
I. Gräßler, P. Scholle ${ }^{\otimes}$ and H. Thiele \\ Paderborn University, Germany \\ $\triangle$ philipp.scholle@hni.uni-paderborn.de
}

\begin{abstract}
To enhance the success of innovations, various methods for foresight have been developed. Automatization yields the potential of shifting effort away from the process to the actual in-depth analysis of resulting scenarios in scenario-technique. Within this paper, an approach based on a userspecific classification of input factors (consistency values) is presented. Generic consistency patterns used for a semi-automatized consistency assessment based on artificial neural networks are identified using a case study approach. Hereby, the effort for scenario-technique can be reduced significantly.
\end{abstract}

Keywords: design automation, design support system, artificial intelligence (Al), scenario technique

\section{Introduction}

The success of new product innovations is characterized by a coincidence of the technological feasibility, the market situation and customer demand for an invention. To identify this strategic gap, various methods for strategic foresight have been developed. One example for strategic foresight is scenario-technique. In addition to conventional approaches towards foresight or portfolio analyses, qualitative aspects and cause-effect relations can be taken into account in a scenario process. The incorporation of system dynamics and the reaction to disruptive events are further advantages of scenario-technique. Yet, scenario-technique is especially common in larger enterprises, but not in start-ups and small and medium enterprises (SMEs) (Tapinos, 2013). One reason is the required effort for application (Mietzner and Reger, 2005; Tapinos, 2013). Automatization of the process of scenario derivation yields the potential of shifting the effort away from scenario derivation to actual in-depth analysis of resulting scenarios (Millett, 2003).

Within this paper, an approach to automatize steps of the scenario generation based on a userspecific classification of input factors (consistency values) is presented. Generic consistency patterns used for a semi-automatized consistency assessment are identified using a case study approach (Yin, 2018). These yield the potential to significantly reduce the effort for application of scenario-technique. Underlying process models for scenario-technique and approaches for semiautomatized consistency assessment are introduced in section 2. In section 3, the research methodology and research questions are described. The identification of generic consistency patterns based on a case study is presented in section 4 . Another case study is used for validation in section 5. An overview of the results and an outlook on future work is given in section 6 . 


\section{State of the art}

This section is divided into three subsections: In section 2.1, a brief introduction into scenariotechnique is given. In section 2.2, the agile process model for strategic planning as an approach towards consistency-based scenario-development is described in details. Existing approaches for semiautomatized consistency assessment are presented in section 2.3.

\subsection{Introduction into scenario-technique}

Based on the military definition of a strategy (Clausewitz, 1832) and the implicit definition of a scenario (Reibnitz, 1992), various schools of scenario-technique were developed. The intuitive logics school was first used for anticipation of military strategies in the cold war (Bradfield et al., 2005) and transferred to strategic foresight by the Club of Rome (Meadows, 1974) and the Shell corporation (Wack, 1985). In the intuitive logics, scenarios are derived in an qualitative, uniformalised approach. A high expertise in scenario development is required due to the lacking formalization. No mathematical modelling and algorithms are used within the process. Here, scenarios are a narrative description of future states of the field of scope.

In contrast to intuitive logics, the cross-impact approaches uses probabilistic modelling for the scenario development (Gordon and Hayward, 1968). Here, influence factors for the future developments within a certain field of scope such as market developments, technological trends or future customer demands are collected, and their interrelations are assessed within the impact matrix. For these influence factors, future developments - projections - are anticipated. Given the occurrence of a projection of one influence factor, the conditional probabilities of the occurrence of projections of other influence factors are assessed by the user (Gordon and Hayward, 1968). The overall probability of scenarios can be calculated by various algorithms using Kolmogorov's axiom. As a result of these algorithms, for each influence factor a projection is selected for the scenario, and the resulting probability of occurrence is mapped to it.

While the success of the intuitive logics school is dependent on the team structure and the expertise in using the method, the cross-impact approaches are more formalized, but strongly dependent on the biased estimation of conditional probabilities (Tversky and Kahneman, 1973; Grienitz et al., 2014).

A high formalization combined with a reduced bias-dependency is offered by the consistency-based approaches. Various process models have evolved (Reibnitz, 1992; Gausemeier et al., 1998; Götze, 1993). Influence factors are described and their interrelations are assessed in analogy to cross-impact approaches. The number of influence factors is reduced by selecting relevant influence factors based on the activity and passivity (Gausemeier et al., 1998). The selection of these key influence factors is heuristic and dependent on scope and time frame of the scenario project. For these key influence factors, projections are derived. Within the consistency matrix, the consistency between projections is assessed pairwise by the user (see Figure 2 in section 2.3 for an example of a consistency matrix). The plausibility of occurrence of two projections within one scenario is described by the consistency assessment as well as the logics and the compatibility (Kosow, 2015). Consistency assessment is the foundation of scenariodevelopment. By means of clustering algorithms and branch-and-bound approaches, scenarios are generated according to the criteria consistency, difference and stability (Mißler-Behr, 1993). From the set of potential raw scenarios, a subset of three to five scenarios is selected. A scenario is a set of projections, containing one projection for each influence factor. These scenarios are then described in a more intuitive format such as prose text (Gausemeier et al., 1998) and presented to the user.

\subsection{Agile process model for strategic planning}

Conventional consistency-based approaches require high effort for data collection and consistency assessment (Mietzner and Reger, 2005; Millett, 2003). To overcome this deficit, a more intuitive, iterative process model was proposed by Gräßler et al. (2017a). Within the agile process model for scenario-technique, the transition between process steps can either be mandatory or optional (see Figure 1). Within the first round of strategic planning, all mandatory transitions have to be passed. Within the strategic planning, the ability to adapt assumptions and decisions taken within the process steps is enabled by the optional transitions: The selection of key influence factors can be adapted in 
later process steps as well as the assumptions for scenario-development. The cause-effect relations of assumptions and the impact on the scenarios are made transparent to the user. Hereby, the intuitivism of the scenarios is improved (Gräßler et al., 2017a), strengthening the communicative function of scenarios for strategic planning (Mietzner and Reger, 2005).

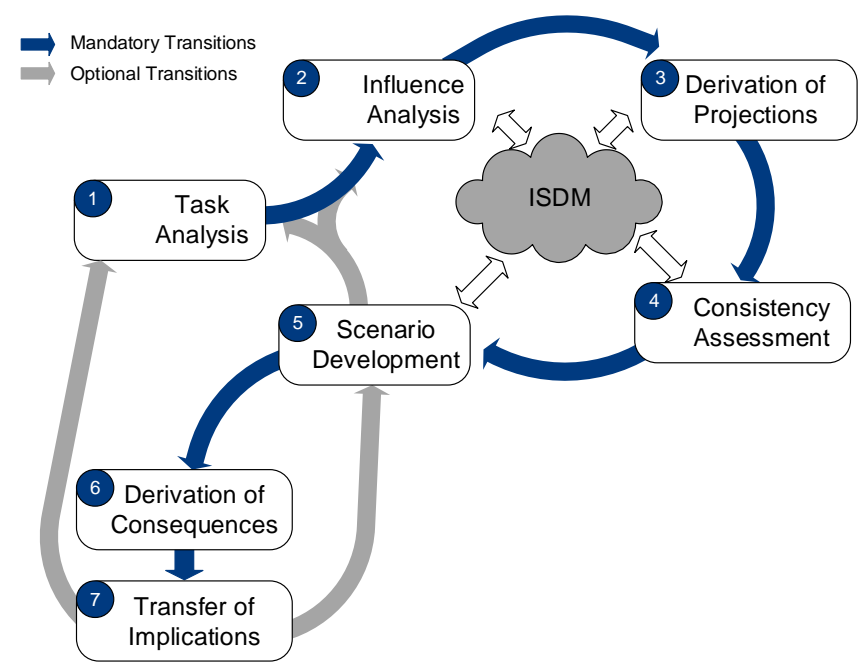

Figure 1. Agile process model for scenario-technique (Gräßler et al., 2017a)

In occurrence of disruptive events or the changing of boundary conditions, the scenarios can easily be adapted to phenomena such as changing societal or technological developments. These adaptations require a reduced effort in scenario adaptation. Within the Integrated Scenario Data Model (ISDM, cf. (Pottebaum and Grässler, 2016)) a collection of influence factors, their interrelations, projections and consistency values has been developed. The ISDM can be tailored to various domains such as innovative service for self-protection in extreme weather (Gräßler et al., 2018) or requirements engineering (Gräßler et al., 2017b). To reduce the heuristic selection of key influence factors from the set of influence factors, novel approaches such as a modified page-rank algorithm have been developed (Gräßler et al., 2019). To reduce the effort for the addition of new influence factors not stored in the ISDM, semi-automatized approaches towards consistency assessment can be used. An approach based on neural networks is described in the following section.

\subsection{Semi-automatized consistency assessment}

The "Consistency Accelerator" is an algorithm, and its implementation to semi-automatize consistency assessment was developed by Dönitz (2009). Here, the triangular and tetragonal relations within the consistency matrix are taken as an input for semi-automatized consistency assessment (Dönitz, 2009). An exemplary consistency matrix is shown in Figure 2 below.

\begin{tabular}{|c|c|c|c|c|c|c|c|c|c|c|c|c|}
\hline $\begin{array}{c}\text { Influence } \\
\text { Factor }\end{array}$ & \multicolumn{2}{|c|}{ Projection } & $1 \mathrm{~A}$ & 1B & $1 \mathrm{C}$ & $2 A$ & 2B 2C: & 3A $3 B$ & $3 C$ & nA & $n B$ & $\mathrm{nC}$ \\
\hline \multirow{3}{*}{$\begin{array}{l}\text { Influence } \\
\text { Factor } 1\end{array}$} & Increase & 1A & & & & 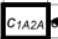 & & & crasc & $c_{\text {TANA }}$ & $c_{\text {TANB }}$ & $C_{\text {TANC }}$ \\
\hline & Stagnation & 1B & & & & & & $\sigma_{1}$ & $c_{183 c}$ & $c_{18 \cap A}$ & $c_{18 \cap 8}$ & $c_{1 B \cap C}$ \\
\hline & Decrease & 1C & & & & & & & $c_{103 c}$ & $C_{1} C_{\mathrm{CA}}$ & $c_{1} C_{\cap B}$ & $c_{1} C_{n C}$ \\
\hline \multirow{3}{*}{$\begin{array}{l}\text { Influence } \\
\text { Factor } 2\end{array}$} & Increase & 2A & $c_{2 A T A}$ & $c_{2 A 1 B}$ & $c_{2 A 1 C}$ & & & C2A3A & $c_{2 A S C}$ & $C_{2 A \cap A}$ & $C_{2 A \cap B}$ & $C_{2 A \cap C}$ \\
\hline & Stagnation & 2B & $C_{2 B 1 A}$ & $C_{2818}$ & $c_{2 B 1 C}$ & & & $C_{2 B 3 A} C_{2 B 3 B}$ & $c_{2 B 3 c}$ & $C_{2 B \cap A}$ & $C_{28 n B}$ & $C_{2 B n C}$ \\
\hline & Decrease & 2C & $c_{2 C 1 A}$ & $c_{2 C 1 B}$ & $c_{2 c 1 c}$ & & & $c_{2 C 3 A} c_{2 C 3 B}$ & $c_{2 c 3 c}$ & $c_{2 \mathrm{CnA}}$ & $c_{2 C n B}$ & $c_{2 \mathrm{CnC}}$ \\
\hline \multirow{3}{*}{$\begin{array}{c}\text { Influence } \\
\text { Factor } 3\end{array}$} & Increase & $3 \mathbf{A}$ & C3ATA & C3A1B & $c_{3 A T C}$ & $C_{3 A 2 A} C$ & $C_{3 A 2 B} C_{3 A 2 C}$ & & & $C_{3 A \cap A}$ & C3AnB & C3AAC \\
\hline & Stagnation & 3B & $C_{3 B 1 A}$ & $C_{3818}$ & $c_{381 c}$ & $C_{3 B 2 A} C$ & \begin{tabular}{|l|l|}
$C_{3 B 28} C_{3 B 2 C}$ \\
\end{tabular} & & & $c_{38 \cap A}$ & $c_{38 n B}$ & $c_{3 B \cap C}$ \\
\hline & Decrease & $3 C$ & $C_{3 C 1 A}$ & $c_{3 C 18}$ & $c_{3 c 10}$ & $c_{3 C 2 A} C$ & $C_{3 C_{2 B} B} C_{3 C_{2 C}}$ & & & $C_{3 \mathrm{CnA}}$ & $\mathrm{C}_{3 \mathrm{C} \mathrm{BB}}$ & $c_{3 \mathrm{CnC}}$ \\
\hline \multirow{3}{*}{$\begin{array}{c}\text { Influence } \\
\text { Factor n }\end{array}$} & Increase & $\mathbf{n A}$ & $C_{n A T A}$ & $C_{\text {CA } 1 B}$ & $C_{n A 1 C}$ & $C_{n A 2 A} C$ & $c_{n A 2 B} c_{n A 2 C} c$ & $c_{n A 3 A} c_{n A 3 B}$ & $c_{n A 3 C}$ & & & \\
\hline & Stagnation & $\mathrm{nB}$ & $C_{n B 1 A}$ & $C_{n B 18}$ & $C_{n B 1 C}$ & $C_{n B 2 A} C$ & $C_{n B 2 B} C_{n B 2 C} c$ & $C_{n B 3 A} C_{n B 3 B}$ & $c_{n в 3 c}$ & & & \\
\hline & Decrease & $\mathrm{nC}$ 。 & $c_{n C 1 A}$ & $c_{n C 1 B}$ & $c_{n C 1 C}$ & $c_{n C 2 A} c$ & $c_{n C 2 B} C_{n C 2 C} C$ & $c_{n C 3 A} c_{n C 3 B}$ & $\mathrm{C}_{\mathrm{nCs}} \mathrm{C}$ & & & \\
\hline
\end{tabular}

Figure 2. Consistency matrix 
The consistency matrix is a symmetrical matrix containing the consistency values. Consistency values $\mathrm{aa}_{\mathrm{ij}}$ can be assessed on various scales (Dönitz, 2009). On a scale between 1 and 5, the value of 1 represents total inconsistency, while high consistency is depicted by a consistency value of 5 . If assessed manually, numerous consistency assessments have to be passed. The number of required consistency assessments can be calculated by the equation below. Here, $\mathrm{E}_{\mathrm{i}}$ denotes the influence factors with $n_{E}=\sum E_{i}$ as the number of influence factors. The number of projections for each influence factor is represented by $\mathrm{p}\left(\mathrm{E}_{\mathrm{i}}\right)$ :

$$
n_{\text {consistency assessments }}=\frac{\sum_{i=1}^{n} n_{E} \cdot p\left(E_{i}\right)-p\left(E_{i}\right)^{2}}{2}
$$

For semi-automatized consistency assessment, the user has to asses a certain number of consistency values in the consistency matrix. In the next step, the consistency values are analysed by assessing the triangular and tetragonal relations in the consistency matrix: In the matrix shown in Figure 2, the triangular relation between influence factors 1, 2 and 3 (with the projections A, B and C) are analysed. By fuzzyfication, pattern recognition using a neural network and defuzzyfication empty fields in the consistency matrix can be completed by triangular and tetragonal relations: Assuming the value $\mathrm{aa}_{23}$ would be missing, the value can be estimated by considering the existing values $\mathrm{aa}_{12}$ and $\mathrm{aa}_{13}$. (Dönitz, 2009)

The implementation of a fuzzy logic is required to increase the accuracy of the semi-automatized consistency assessment. Fuzzy numbers can be used since consistency values are often fuzzy - given the example of the consistency of two projections, users can hardly distinguish between a consistency value of 4 or 5 (Dönitz, 2009). The semi-automatized consistency assessment can be improved by considering grouped consistency values (Dönitz, 2009). The grouping only considers consistency between two projections, but not the consistency between all projections of two different influence factors.

\section{Research gap and methodology}

As outlined in section 2.3, the consistency accelerator can be improved by grouped consistency values. Semi-automatized consistency assessments yield the potential to significantly reduce the effort for consistency assessment (Dönitz, 2009; Gräßler et al., 2018) and hereby to even increase agility in the agile process model of scenario-technique. Grouping of consistency values can improve the performance of the semi-automatized consistency assessment (Dönitz, 2009). Yet, only single projections are grouped. Based on this problem description, the following research questions were derived:

1. Can generic groups of consistency values (consistency patterns) be identified?

2. How can consistency values within a consistency matrix be classified into consistency patterns efficiently?

3. In which way can semi-automatized consistency assessment be improved by these consistency patterns?

To answer the research questions, a case study-basis approach was chosen. The case study was structured according to the case study approach proposed by Yin (2018). Phases herein are the planning and design of the case study, preparation and data collection, data analysis and publication (Yin, 2018).

\section{Semi-automatic consistency assessment based on consistency patterns}

The case study was derived from the EU H2020 funded research project "ANYWHERE". In the case study, students were asked to derive scenarios for the market of innovative tools and services based on a platform offering forecasting algorithms and impact assessments for high impact weather. Sixteen influence factors and their projections were pre-defined. Thirteen influence factors were described by three projections each, while three of the influence factors were defined by two projections each. An example for one influence factor and its projections is shown in Table 1. Participants were asked to fill in the consistency matrix. A total number of 100 consistency matrices was submitted. Participants were allowed to work in teams of up to 5 members. The team members were mentioned during the submission process. For each team, only one consistency matrix was considered. The overall number of consistency 
matrices analysed was 56. From the case study, generic consistency patterns as well as rules for the semi-automatized consistency assessment were derived.

Table 1. Description and projections of the influence factor B1 "Potential threat by extreme weather events" (Gräßler et al., 2018)

\begin{tabular}{|c|c|c|c|c|c|c|}
\hline \begin{tabular}{|c|}
$\begin{array}{c}\text { Influence } \\
\text { field }\end{array}$ \\
\end{tabular} & \# & Name & Source & Description & $\begin{array}{c}\text { Projection } \\
\text { ID }\end{array}$ & Description of projection \\
\hline \multirow{3}{*}{$\begin{array}{l}\frac{\lambda}{0} \\
\frac{0}{0} \\
0 \\
\text { i }\end{array}$} & \multirow{3}{*}{1} & \multirow{3}{*}{$\begin{array}{c}\text { Potential } \\
\text { threat by } \\
\text { extreme } \\
\text { weather } \\
\text { events }\end{array}$} & \multirow{3}{*}{$\begin{array}{c}\text { Data base } \\
\text { (MunichRE) }\end{array}$} & \multirow{3}{*}{$\begin{array}{l}\text { This influence } \\
\text { factor describes the } \\
\text { real (measureable) } \\
\text { global threat by } \\
\text { extreme weather } \\
\text { events. }\end{array}$} & $1 \mathrm{~A}$ & $\begin{array}{c}\text { The number of extreme weather } \\
\text { events increases up to } 825 \text { per annum } \\
\text { globally. }\end{array}$ \\
\hline & & & & & $1 \mathrm{~B}$ & $\begin{array}{l}\text { The number of extreme weather } \\
\text { events remains constant at a number of } \\
750 \text { events per annum globally. }\end{array}$ \\
\hline & & & & & $1 \mathrm{C}$ & $\begin{array}{l}\text { The number of extreme weather } \\
\text { events decreases to } 675 \text { events per } \\
\text { annum globally. }\end{array}$ \\
\hline
\end{tabular}

\subsection{Identification of generic consistency patterns and classification}

For the analysis of the case study, all 56 matrices were considered. The idea is to identify generic consistency patterns. A consistency pattern is based on all projections of an influence factor and the related consistency assessments. Thereby, the fundamental relation between all projections of one influence factor to all other projections of another influence factor is represented. Instead of considering all nine consistency values in a submatrix of two influence factors with three projections each (e.g. influence factors 1 and 2 in Figure 3 below), only one consistency pattern $k_{i j}\left(\right.$ here: $k_{12}$ ) is used for semi-automatized consistency assessment.

\begin{tabular}{|c|c|c|c|c|c|c|c|c|c|c|c|c|c|c|c|c|}
\hline $\begin{array}{c}\text { Influence } \\
\text { Factor }\end{array}$ & \multicolumn{2}{|c|}{ Projection } & 1A $1 \mathrm{~B}$ & $1 \mathrm{C}$ & $2 A 2 B 2 C$ & $3 A 3 B$ & $3 C$ & nA & $n B$ nC & $\begin{array}{l}\text { Influence } \\
\text { Factor }\end{array}$ & \multicolumn{2}{|c|}{ Projection } & 1A 1B 1C & $2 A 2 B 2 C$ & $3 A 3 B 3 C$ & $n A n B n C$ \\
\hline \multirow{3}{*}{$\begin{array}{l}\text { Influence } \\
\text { Factor } 1\end{array}$} & Increase & 1A & & & ${ }_{1 A 2 A} C_{1 A 2 B} C_{1 A 2}$ & $c_{\text {TASA }} c_{1 A 3 B}$ & $c_{1} c_{1 A s c}$ & $c_{\text {TANA }}$ & \begin{tabular}{|c|c|}
$c_{1 A n B}$ & $\sigma_{\operatorname{tanC}}$ \\
\end{tabular} & \multirow{3}{*}{$\begin{array}{l}\text { Influence } \\
\text { Factor } 1\end{array}$} & Increase & 1A & & \multirow{3}{*}{$k_{12}$} & \multirow{3}{*}{$k_{13}$} & \multirow{3}{*}{$k_{1 n}$} \\
\hline & Stagnation & 1B & & & 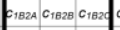 & $c_{1834} c_{1838}$ & ${ }_{8} C_{1830}$ & $c_{18 \mathrm{~B} A \mathrm{~A}}$ & $c_{18 n B} c_{1 B n C}$ & & Stagnation & 1B & & & & \\
\hline & Decrease & $1 \mathrm{C}$ & & & $10221 \mathrm{C}_{11028} \mathrm{C}_{102}$ & $c_{1}+23 n c_{1} \cos \theta$ & $a_{10} c_{c s c}$ & $c_{1} \mathrm{COA} A$ & $c_{1} \operatorname{COB} B c_{1} \operatorname{COC}$ & & Decrease & 1C & & & & \\
\hline \multirow{3}{*}{$\begin{array}{c}\text { Influence } \\
\text { Factor } 2\end{array}$} & Increase & 2A & $c_{24 A} c_{2 A 1}$ & ${ }_{8} c_{2 A 1 C}$ & & $c_{2 A 3 A} c_{2 A 3 B}$ & $c_{2 A 3 C}$ & $c_{2 A N A}$ & $c_{2 A A B} c_{2 A A C}$ & \multirow{6}{*}{$\begin{array}{l}\text { Influence } \\
\text { Factor } 3\end{array}$} & Increase & 2A & \multirow{3}{*}{$k_{21}$} & & \multirow{3}{*}{$k_{23}$} & \multirow{3}{*}{$k_{2 n}$} \\
\hline & Stagnation & 2B & $c_{281 A} c_{28}$, & ${ }_{B} c_{2 B B C}$ & & $c_{233 A} c_{2838}$ & ${ }_{8} c_{233 c}$ & $c_{2 B n A}$ & $c_{28 n B} C_{C}$ & & Stagnation & 2B & & & & \\
\hline & Decrease & 2C & $\mathrm{C}_{2 \mathrm{COA}} \mathrm{C}_{2 \mathrm{C}}$ & ${ }_{80} c_{2010}$ & & $c_{2238} c_{22038}$ & (1) $c_{2030}$ & $c_{2 \mathrm{CAA}}$ & $c_{2 C D B} c$ & & Decrease & $2 \mathrm{C}$ & & & & \\
\hline \multirow{3}{*}{$\begin{array}{c}\text { Influence } \\
\text { Factor } 3\end{array}$} & Increase & 3A & $c_{3 A A A} c_{3 A}$ & ${ }_{8} c_{3 A+C} C$ & $c_{342 A} C_{3 A 28} C_{3 A 2 C}$ & & & csanA & $\operatorname{coshn} \theta d$ & & Increase & $3 \mathbf{A}$ & \multirow{3}{*}{$k_{31}$} & \multirow{3}{*}{$k_{32}$} & & \multirow{3}{*}{$k_{3 n}$} \\
\hline & Stagnation & 3B & $c_{381 \times} c_{398}$ & ${ }_{8} c_{3811} \mathrm{C}$ & $c_{3 B 2 A} C_{3828} C_{982 C}$ & & & csena & $c_{\operatorname{csen} e} c_{3 \operatorname{sen} C}$ & & Stagnation & $3 B$ & & & & \\
\hline & Decrease & $3 C$ & $\operatorname{coscta}_{13} c_{31}$ & ${ }_{8 \mathrm{Cacic} C \mathrm{C}}$ & $C_{3 C 2 A} C_{3 C 2 B} C_{3 C 2 C}$ & & & $c_{3 C A A}$ & $C_{3 C B B} C_{3 C A C}$ & & Decrease & $3 C$ & & & & \\
\hline \multirow{3}{*}{$\begin{array}{l}\text { Influence } \\
\text { Factor n }\end{array}$} & & & & & & & & & & \multirow{3}{*}{$\begin{array}{l}\text { Influence } \\
\text { Factor } n\end{array}$} & & & \multirow[b]{3}{*}{$k_{n 1}$} & \multirow[b]{3}{*}{$k_{n 2}$} & \multirow[b]{3}{*}{$k_{n 3}$} & \\
\hline & Increase & nA & CnAAA $C_{\text {nAt }}$ & 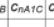 & $C_{n A 2 A} C_{n A 2 B} C_{n A 2 C}$ & $c_{n A 3 A} c_{n A B B}$ & $8 c_{n a s c}$ & & & & Increase & nA & & & & \\
\hline & Stagnation & nB & $C_{n B A} A C_{n B}$ & 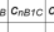 & $=C_{n B 2 A} C_{n B Z B} C_{n B 2 C}$ & $c_{n B 3 A} c_{n B 38}$ & $c_{n B 3 c}$ & & & & Stagnation & $\mathrm{nB}$ & & & & \\
\hline
\end{tabular}

Figure 3. Consistency matrix with all consistency values in one submatrix (left) and consistency patterns (right)

In order to compare the consistency patterns among both, different scenario projects and users, the formulations of projections are standardized: the first projection describes an increase, the second a stagnation while the third projection contains a decrease of the influence factor. In an analysis of all (sub-)matrices in the case study, patterns could be identified: for influence factors and their consistency assessments either supporting (proportional), neutral or contrary (antiproportional) behaviour was assumed by the participants. Exemplary submatrices are shown in Figure 4.

\begin{tabular}{|c|c|c|c|}
\hline & 2A & 2B & 2C \\
\hline 1A & 5 & 2 & 1 \\
\hline 1B & 1 & 5 & 3 \\
\hline 1C & 1 & 1 & 5 \\
\hline
\end{tabular}

supporting

\begin{tabular}{|c|c|c|c|}
\hline & 2A & 2B & 2C \\
\hline 1A & 3 & 3 & 3 \\
\hline 1B & 3 & 3 & 3 \\
\hline 1C & 3 & 3 & 3 \\
\hline
\end{tabular}

neutral

\begin{tabular}{|c|c|c|c|}
\hline & 2A & 2B & 2C \\
\hline 1A & 5 & 2 & 2 \\
\hline 1B & 1 & 4 & 1 \\
\hline 1C & 2 & 1 & 5 \\
\hline
\end{tabular}

contrary

Figure 4. Exemplary submatrices identified in the case study 
Supporting and contrary patterns can be classified by the position of the high consistency values within the submatrix: in a supporting case, high entries appear on the diagonal of the matrix, while in a contrary case, these can be found on the counterdiagonal. To differentiate, two values are used to classify the matrices:

- The sum of elements on the diagonal, (in case of the $3 \times 3$ submatrix marked in Figure 3)

- The sum of elements on the counterdiagonal, (in case of the $3 \times 3$ submatrix marked in Figure 3)

$$
\begin{array}{ll}
\text { i.e. } & S_{D}=c_{1 A 2 A}+c_{1 B 2 B}+c_{1 C 2 C} \\
\text { i.e. } & S_{C}=c_{1 A 3 C}+c_{1 B 2 B}+c_{1 C 2 A}
\end{array}
$$

Given a maximum consistency value of five for each element in the matrix, the maximum value of $S_{D}$ and $S_{C}$ is 15 for a $3 \times 3$ submatrix. The criteria and related consistency patterns shown in Figure 5 were derived based on both $S_{D}$ or $S_{C}$. The middle value on both diagonals in a submatrix is considered to be able to distinguish the neural consistency pattern K5 from others. The quantity of the submatrices characterized as the different consistency patterns is given in Table 2.

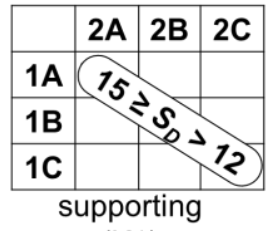

(K1)

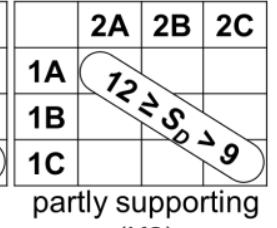

(K2)

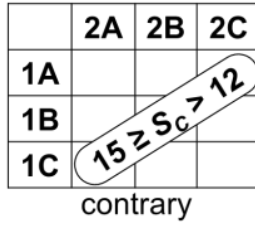

(K3)

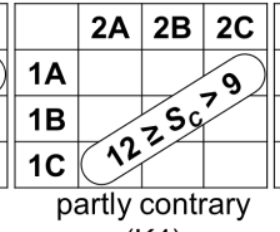

(K4)

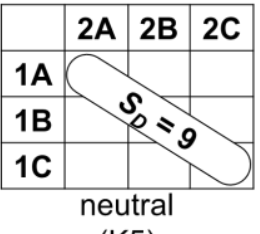

(K5)

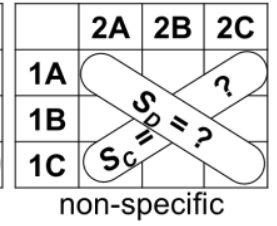

(K6)

Figure 5. Consistency patterns and identification criteria

Table 2. Consistency patterns and relative occurrence in the case study

\begin{tabular}{|c|c|c|c|c|c|c|}
\hline consistency pattern & $\mathrm{K} 1$ & $\mathrm{~K} 2$ & $\mathrm{~K} 3$ & $\mathrm{~K} 4$ & $\mathrm{~K} 5$ & $\mathrm{~K} 6$ \\
\hline relative occurrence $3 \times 3[\%]$ & 21,15 & 22,43 & 21,15 & 22,43 & 0,67 & 12,16 \\
\hline relative occurrence $2 \times 2[\%]$ & 13,79 & 27,01 & 15,52 & 27,01 & 8,62 & 8,05 \\
\hline relative occurrence $2 \times 3[\%]$ & 21,17 & 23,60 & 21,17 & 23,60 & 5,19 & 5,27 \\
\hline
\end{tabular}

To classify the consistency patterns, a pattern recognition based on a neural network was trained. The neural network was a two-layer feed-forward network with ten hidden layer and six output layer neurons. The network was trained with a scaled conjugate gradient backpropagation. Mathworks Matlab' neural network toolbox was used for programming. $70 \%$ of all case study values were used for training, $15 \%$ for testing and $15 \%$ for validation. The confusion matrix, as a measure of accuracy, is shown below.

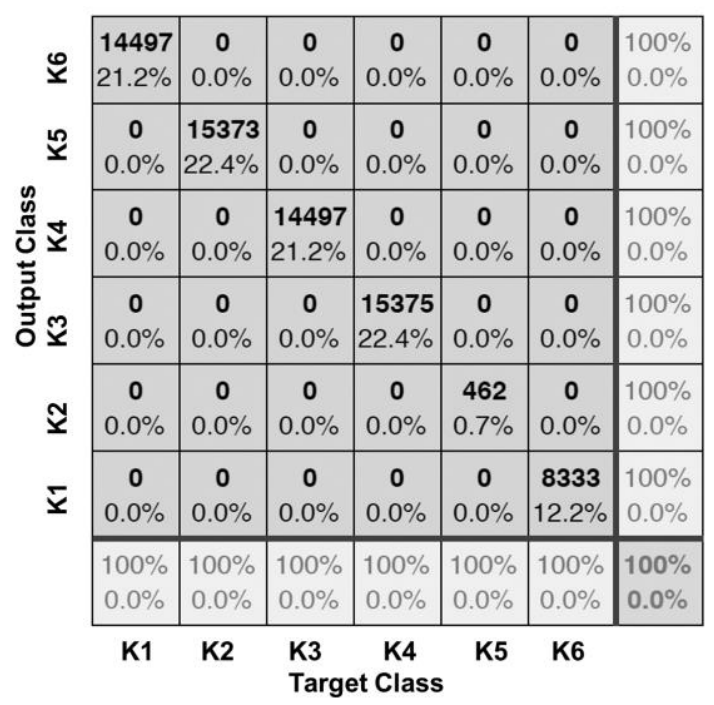

Figure 6. Confusion matrix for the classification of consistency patterns 
When applying the neural network to the case study, the confusion matrix (Figure 6) shows that submatrices can be classified into consistency patterns correctly. These consistency patterns will be used for a semi-automatized consistency assessment described in the following section of the paper.

\subsection{Semi-automatized consistency assessment based on consistency patterns}

Given the correct consistency pattern for the consistency assessments between two influence factors, missing consistency patterns can be assessed semi-automatically by analysing the triangular and tetragonal relations between the influence factors. In Figure 7, an example is given: all values within the submatrix characterized by the consistency pattern $\left(\mathrm{k}_{12}\right)$ between influence factors 1 and 2 are missing. The consistency pattern can be assessed semi-automatically, given the relations of influence factors 1 and $3\left(\mathrm{k}_{13}\right.$, consistency pattern: $\left.\mathrm{K} 1\right)$ in combination with influence factors 2 and $3\left(\mathrm{k}_{23}\right.$, consistency pattern: K1) (see Figure 7).

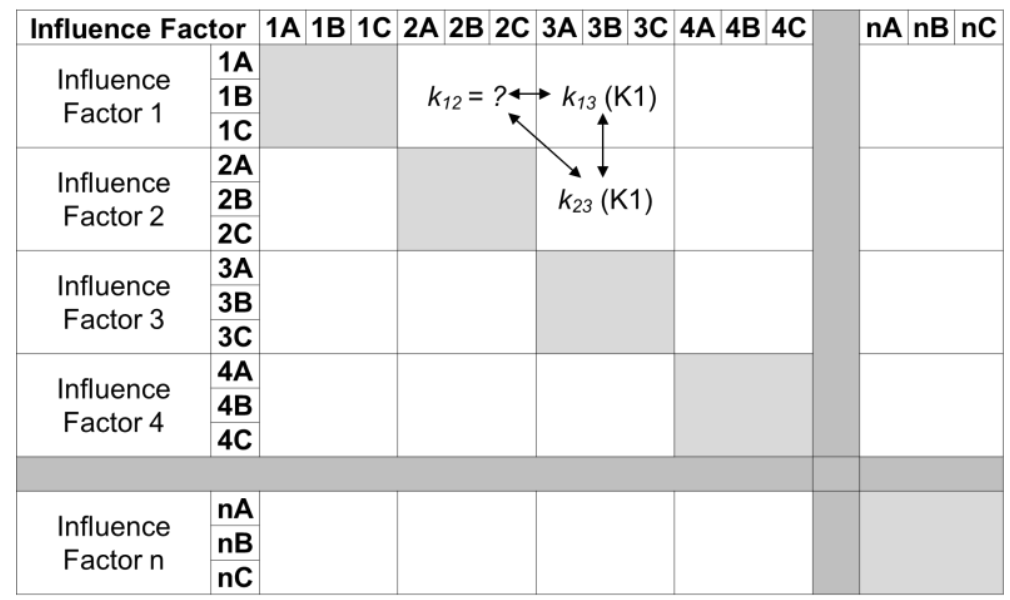

Figure 7. Semi-automatized consistency assessment based on consistency patterns

To derive rules for the semi-automatized consistency assessment, all triangular (total number: 94'080) and tetragonal relations (total number: 1'223'040) were analysed. Rules were derived on an empirical basis. Results of the empirical analysis for triangular relations and the resulting ruleset are given in Figure 8.

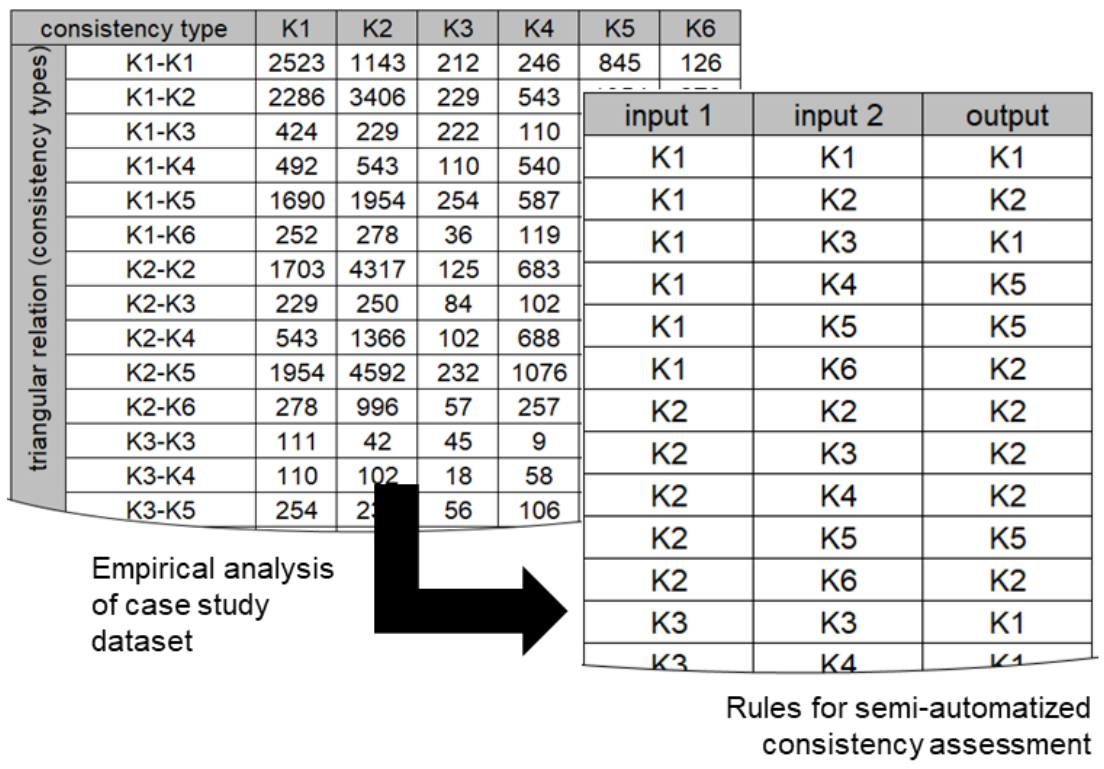

Figure 8. Results of the empirical analysis for triangular relations and the derived rules for semi-automatized consistency assessment (based on case study data) 
The rule set was used as an input for a semi-automatized consistency assessment. For each missing consistency pattern of a submatrix a number of potential consistency patterns can be generated based on triangular and tetragonal relations. From this set, the consistency pattern with the highest probability is chosen. The procedure can be repeated for further missing entries in the consistency matrix.

Considering the influence factor 1 from Table 1 "Potential threat by extreme weather events", the consistency type of the $3 \times 3$ submatrix $\left(\mathrm{k}_{12}\right)$ for influence factor 2 "Customers subjective fear of extreme weather events" can be assessed semi-automatically given the consistency types of the tetragonal relation with influence factor 3 "Impact of climate change" in relation to influence factors 1 and $2\left(\mathrm{k}_{13}\right.$ and $\left.\mathrm{k}_{23}\right)$. Considering further design applications such as product planning or technological forecasting, influence factors considered could be the potential technological capability or the potential customer demand for a certain product.

By applying the method, the effort for consistency assessment can be significantly reduced, thereby increasing the agility within the agile process model. Once new influence factors are added to the set of key influence factors, most of the consistency values can be assessed semi-automatically based on the analysis of the submatrices and related consistency patterns within the already-filled in part of the consistency matrix. The method for semi-automatized consistency assessment based on consistency patterns was validated with the case study data. Validation results for the semi-automatized consistency assessment are presented in the following section.

\section{Validation}

To validate the results of the semi-automatized consistency assessment based on consistency patterns, consistency matrices from the case study dataset have been used. After a classification based on the neural network (see section 5 for details on the validation of the classification of consistency patterns), rules and methods for semi-automatized consistency assessment were applied. To measure the results qualitatively, the effective matching factor was used:

$$
Q_{e f f}=\frac{M_{P}}{M_{P}+M_{N}}
$$

Here, $M_{P}$ is the overall number of correctly assigned consistency patterns in former empty fields while $\mathrm{M}_{\mathrm{N}}$ represents the number of incorrectly assigned consistency patterns in former empty fields. Results of the validation for both, triangular-only and tetragonal-only consistency assessment are presented in Figure 9 below. For each filling level, ten matrices from the dataset were selected at random. Therein, the relevant number of submatrices was deleted randomly, imitating empty fields in the consistency matrix.

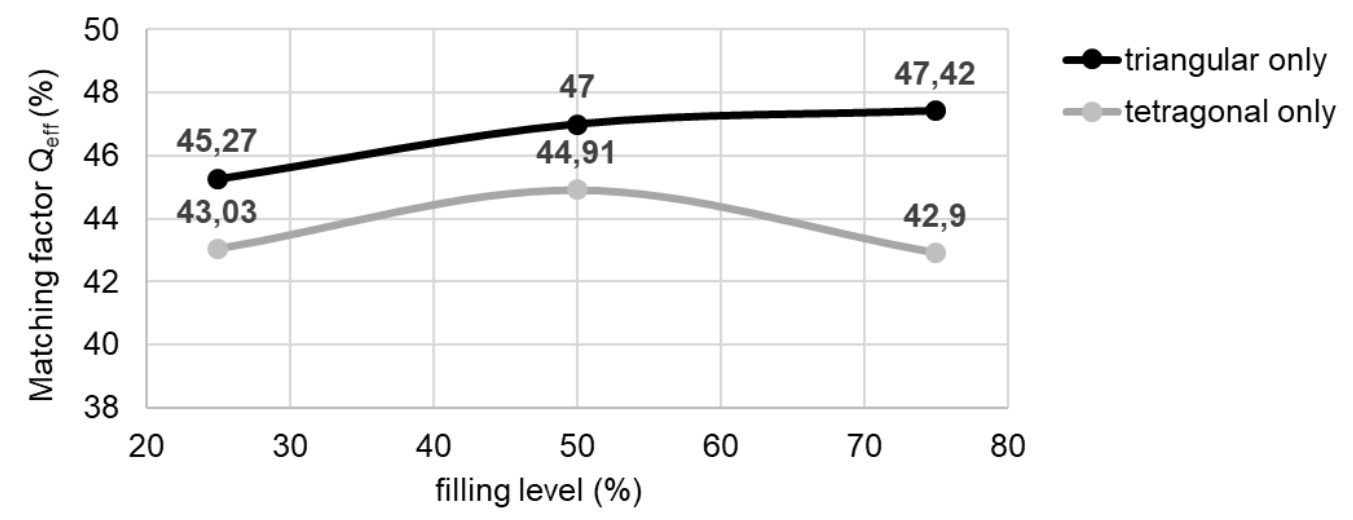

Figure 9. Validation results for semi-automatized consistency assessment

The matching factor is highest for a semi-automatized consistency assessment based on triangular relations only. For tetragonal relations, $Q_{\text {eff }}$ is generally lower and even decreasing further with an increase in filling level. The impact of filling level on the matching factor is positive for triangular relations. Nevertheless, the increase of matching factor in relation to higher effort for earlier manual consistency assessment is marginal. Given $25 \%$ of the consistency types, $45,27 \%$ of the missing 
consistency types can be assessed correctly by the semi-automatized consistency assessment. These values show the capability of the approach to support consistency assessment. Given the consistency type, values within the submatrices can be regained by an empirical approach: all submatrices of a type and the consistency values therein are analysed and statistical distributions for single entries within the submatrices are generated. Based on these distributions, values within the submatrices can be regained dependent on the underlying consistency pattern. Derivation of such statistical distributions will be part of future work.

\section{Summary and outlook}

Within this paper, a novel approach for semi-automatized consistency assessment within the agile process model of scenario-technique was presented. The approach yields the potential to significantly reduce the application effort of scenario-technique by enhancing the agility of the process model. The workload for manual consistency assessments is reduced by a semi-automatized consistency assessment based on consistency patterns. These are classified by pattern recognition based on neural networks. By applying consistency patterns rather than singular consistency values, a broader dataset can be generated from the manually assessed consistency values within the consistency matrix. The usage of consistency patterns allows a more abstract semi-automatized consistency assessment. Nonetheless, characteristic behaviour and patterns within the consistency matrix can be depicted during the process.

Benefits of semi-automatized consistency are a reduced effort for consistency assessment. Hereby, new influence factors can be added to the set of key influence factors more efficiently. By an overall reduction of effort, scenario-technique can be used by a broader set of users. Enabling a better anticipation of the strategic gap between technological feasibility, market and consumer demands, the success rate for innovation can be enhanced in new product development.

In future work, the generation of submatrices from the consistency patterns will be in focus. Here, an empirical analysis with statistical distributions of consistency values for certain consistency patterns will be implemented. Within the method for semi-automatized consistency assessment, the combination of triangular and tetragonal relations yields the potential to increase the matching factor. Another approach could be the neglection of neutral (K5) consistency patterns for a further increase in accuracy. Despite methodological improvements, the approach will be tested with further datasets from both, the industrial practice and research.

\section{Acknowledgements}

The ANYWHERE project has received funding from the European Research Council (ERC) under the European Union's Horizon 2020 research and innovation program under grant agreement No 700099.

\section{References}

Bradfield, R. et al. (2005), "The origins and evolution of scenario techniques in long range business planning", Futures, Vol. 37 No. 8, pp. 795-812.

Clausewitz, C.V. (1832), Vom Kriege, Berlin.

Dönitz, E.J. (2009), Effizientere Szenariotechnik durch teilautomatische Generierung von Konsistenzmatrizen: Empirie, Konzeption, Fuzzy- und Neuro-Fuzzy-Ansätze, Gabler Verlag, Wiesbaden.

Gausemeier, J., Fink, A. and Schlake, O. (1998), "Scenario Management", Technological Forecasting and Social Change, Vol. 59 No. 2, pp. 111-130.

Gordon, T.J. and Hayward, H. (1968), "Initial experiments with the cross impact matrix method of forecasting", Futures, Vol. 1 No. 2, pp. 100-116.

Götze, U. (1993), Szenario-Technik in der strategischen Unternehmensplanung, DUV. Wirtschaftswissenschaft, 2nd ed., Dt. Univ.-Verl. [u.a.], Wiesbaden.

Gräßler, I., Pottebaum, J. and Scholle, P. (2017a), "Integrated Process and Data Model for Agile Strategic Planning", paper presented at IDE Workshop, 05.04. - 07.04., Magdeburg.

Gräßler, I., Pottebaum, J. and Scholle, P. (2018), "Influence Factors for Innovation in Digital Self-Preparedness Services and Tools", International Journal of Information Systems for Crisis Response and Management, Vol. 10 No. 1, pp. 20-37. 
Gräßler, I., Scholle, P. and Pottebaum, J. (2017b), "Integrated process and data model for applying scenariotechnique in requirements engineering", In: Design Society (Ed.), ICED17: 21st International Conference on Engineering Design Vancouver, 21.-25.08.2017, Design Society, pp. 261-270.

Gräßler, I., Thiele, H. and Scholle, P. (2019), "Methode zur Einflussanalyse in der SzenarioTechnik auf Basis gerichteter Graphen", in DFX 2019: Proceedings of the 30th Symposium Design for X, 18-19 September 2019, Jesteburg, Germany, 18th-19th September 2019, The Design Society.

Grienitz, V., Hausicke, M. and Schmidt, A.-M. (2014), "Scenario development without probabilities-focusing on the most important scenario", European Journal of Futures Research, Vol. 2 No. 1.

Kosow, H. (2015), "New outlooks in traceability and consistency of integrated scenarios", European Journal of Futures Research, Vol. 3 No. 1, p. 16.

Meadows, D.H. (1974), The limits to growth: A report for the Club of Rome's Project on the Predicament of Mankind, 2nd ed., Universe Books, New York.

Mietzner, D. and Reger, G. (2005), "Advantages and Disadvantages of Scenario Approaches for Strategic Foresight", International Journal Technology and Intelligence Planing, Vol. 1 No. 2, pp. 220-239.

Millett, S.M. (2003), "The future of scenarios. Challenges and opportunities", Strategy \& Leadership, Vol. 31 No. 2, pp. 16-24.

Mißler-Behr, M. (1993), Methoden der Szenarioanalyse, DUV Wirtschaftswissenschaft, Dt. Univ.-Verl., Wiesbaden.

Pottebaum, J. and Grässler, I. (2016), "Reliable Input for Strategic Planning: The Integrated Scenario Data Model”, In: Villmer, F.-J. and Padoanao, E. (Eds.), 6th International Conference Production Engineering and Management, pp. 99-110.

Reibnitz, U.V. (1992), Szenario-Technik: Instrumente für die unternehmerische und persönliche Erfolgsplanung, 2nd ed., Gabler, Wiesbaden.

Tapinos, E. (2013), "Scenario planning at business unit level”, Futures, Vol. 47, pp. 17-27.

Tversky, A. and Kahneman, D. (1973), "Availability. A heuristic for judging frequency and probability", Cognitive Psychology, Vol. 5 No. 2, pp. 207-232.

Wack, P. (1985), "Scenarios: Shooting the Rapids", Harvard Buisness Review, Vol. 63 No. 6, pp. 139-150.

Yin, R.K. (2018), Case study research and applications: Design and methods, Sixth edition, SAGE, Los Angeles, London, New Dehli, Singapore, Washington DC, Melbourne. 